удК 82

\title{
Е.А. Балашова
}

\section{«ПОДПОЛЬНЫЙ» ВАРИАНТ ИДИЛЛИИ В ПОЭЗИИ ГЕОРГИЯ ОБОЛДУЕВА}

В статье дана интерпретация ранних текстов Георгия Николаевича Оболдуева (1889-1954), которые считаются трудными для восприятия, отличаются «затемненным» смыслом. Вместе с тем идиостиль поэта характеризуется не только прихотливыми ассоциативными связями, но и очень точным и ответственным словоупотреблением. Учет этих особенностей позволяет обнаружить в «сложных» стихотворениях традиционные идиллические мотивы.

Идиллия в рассмотренных отрывках существует у Г. Оболдуева как архетип, как подсознательный концепт бытия, в жизни не претворенный. Можно говорить, что у Оболдуева существует «подпольный» вариант идиллии. Необычная поэтика идиллической лирики соответствует поэтике раннего периода творчества поэта: изощренная игра слов, реалистичная деталь, яркая образность, интертекстуальность, «эклектизм стиля», лексическое разнообразие.

Выделенные нами строки обнажают важное для Г. Оболдуева положение о «целительной» роли культуры. Показательно, что этот образ встречается у поэта неоднократно, становясь устойчивым мотивом.

Ключевые слова: русская поэзия ХХ века, Г. Оболдуев, идиостиль поэта, идиллия.

DOI: $10.35634 / 2412-9534-2021-31-3-589-594$

Фигура Георгия Оболдуева, автора необычных, эпатирующих стихов, всё ещё мало известна даже в филологических кругах. Известен Г. Оболдуев стал благодаря воспоминаниям его супруги Е. Благининой, изысканиям В. Глоцера, Н. Яновского и И. Ахметьева. Стоит отметить и особую роль Л.А. Озерова в открытии стихов Оболдуева. Однако и теперь, несмотря на уже неоднократные публикации поэта и ряд статей о нем (на выход его книг откликнулись Г. Айги, И. Роднянская, Д. Давыдов, Ю. Нечипоренко, М. Айзенберг и другие, о поэте писал М. Гаспаров, а Е. Евтушенко напечатал подборку его стихов в своей антологии «Строфы века»), лирика Оболдуева, как и вехи его биографии, малоизвестны.

Назовем несколько фактов биографии для общего представления о поэте по статье В. Глоцера правда, в очень кратком изложении: «Георгий Николаевич Оболдуев родился в Москве в 1898 году в дворянской семье среднего достатка. Отец его был предводителем дворянства в Ковровском уезде Владимирской губернии, и семье принадлежало небольшое родовое имение Дорки, неподалеку от Шуи (Оболдуевы - старинная русская фамилия, упоминаемая в «Кому на Руси жить хорошо»). В 1908 году умирает отец Оболдуева, в 1909-м - мать, оставив его с сестрой Юлией, которая была старше на год, сиротами. Детей воспитывала сестра отца Ольга Платоновна Янушко; однако она скоро умерла, и дети оказались на попечении ее дочери, Людмилы Иосифовны Янушко. В 1916 году Оболдуев окончил московскую гимназию в память императора Александра III и поступил на историко-филологический факультет Московского университета. Проучился 3 курса, и пришлось идти на Гражданскую войну. Он попал в 19-й тяжелый артиллерийский дивизион, откуда в 1922 году был уволен в запас.

Осенью 1921 года Оболдуев поступил на III курс Высшего литературно-художественного института имени В. Я. Брюсова, который окончил в 1924 году, но без защиты диплома. Важной вехой его биографии является то, что многие годы, еще с дореволюционных лет, Оболдуев серьезно занимался музыкой. В 1917 году он окончил музыкальную школу имени Визлер. В молодости брал уроки у известной пианистки Е. Бекман-Щербины. Будучи студентом, участвовал как пианист в вечерних концертах.

Стихи, по собственному признанию, Оболдуев писал с 14-15 лет, они не сохранились. Но обращение к поэзии в детстве не было случайным. Георгий Оболдуев стремился получить именно литературное, филологическое образование. Он владел несколькими европейскими языками.

По выходе из Брюсовского Института Оболдуев начал служить в издательствах: в ГИЗе, в Партиздате, в Профиздате. Причем это не всегда была работа литературного редактора, но также и редактора технического, заведующего оформительским отделом, корректора... Однако, хотя в 1920-е годы Оболдуев не печатался, он вращался в литературных кругах, посещал, в частности, «Никитин- 
ские субботники». В начале 1929 года вместе с приятелями подписал декларацию «Союза приблизительно равных».

В самом конце 1933 года Оболдуев был арестован и обвинен по статье «агитация и пропаганда... призыв к свержению советского строя...». В постановлении об избрании меры пресечения было сказано, что «Оболдуев <..> нелегально распространял контрреволюционные литературные произведения» (речь шла о произведениях М. Цветаевой).

По возвращении из административной высылки Оболдуев не имел права жить в Москве. Он жил в Малоярославце. В 1943 году Оболдуева мобилизовали и отправили на фронт. С мая 1943-го по август 1944-го он воевал разведчиком в 336-м разведывательном противотанковом дивизионе. Когда в августе 1944 года дивизион переформировали, Оболдуев попал в запасный полк. На фронте он был контужен, и последствием контузии оказалась тяжелая форма гипертонии.

После демобилизации в 1945-м его жизнь не стала легче. Оригинальные стихи по-прежнему не печатали - только переводы» [5. С. 3].

Творчество Г. Оболдуева всегда отличала большая степень оригинальности и особая форма переосмысления традиционного. Данную авторскую особенность необходимо учитывать и при рассмотрении жанрологии художественного мира произведений поэта. Бытование лирических жанров в поэзии XX века остается одной из непроясненных проблем современного литературоведения. Сложность жанрового чтения и жанровой классификация отмечается во многих работах ученых: у О.В. Зырянова [6], у Н.Л. Лейдермана [9], у Л.Г. Фризмана [12] и др. Попытки проследить судьбу отдельных жанров были предприняты в работах, посвященных жанру оды [2], идиллии [3], послания [7], эпиграммы [10]... Авторы названных работ считают, что исторически сложившиеся жанры сохраняются и после распада жанровой системы в трансформированном виде. Лирика Г. Оболдуева не стала исключением.

Цель данной статьи - найти жанрообразующие признаки идиллии, учитывая принцип авторской индивидуальности в восприятии данного жанра, поскольку, анализируя судьбу отдельного жанра, можно обнаружить те общие закономерности, которые позволяют говорить об особенностях жанрообразования в поэтике автора.

Вот, например, в жанровом репертуаре Георгия Оболдуева нашлось место традиционной стихотворной идиллии. Таковы, например, стихотворения «Ржал в траве кузнечик», «Сельская идиллия», «Обычное право», «Солдат», «Эклога», «Осенний лес»... Рассмотрим одно из них:

Скачет босой жеребец.

Тащит мальчонка хомут.

Девочка гонит овец.

Встречные ветры поют.

Нежен вечерний простор

Голых весенних полей.

Неба кисейный узор

Льется по коже моей.

Я - городской завсегдатай -

Еду землёй конопатой,

В дряблой телеге трясусь,

Пыли гутирую вкус.

\author{
Волей белья и еды \\ Ближе мне улиц ряды: \\ Обыкновенный уют, \\ Где ундервуды поют. \\ Ближе мне служащих бег; \\ Нежной бездельницы кольца; \\ Быстрые двери аптек; \\ Крепкая рысь комсомольца; \\ Нервных трамваев возня; \\ И сам я день ото дня \\ 7.V.1927 [11. C. 132]
}

«Скачет босой жеребец...»- единственное стихотворение, опубликованное при жизни поэта, состоит из двух неравных строф. Первая часть - 12 строк - это сельская картина, увиденная «городским завсегдатаем», который живо реагирует на природу. Помимо прямой констатации деревенских реалий («Мальчик тащит хомут / Девочка гонит овец»), лирический герой «гутирует» «живые» образы окружающего («босой жеребец», «еду землей конопатой»). Однако, несмотря на симпатию к виду вечернего простора, несмотря на подчеркнутую собственную «природность» («Неба кисейный узор / Льется по коже моей»), он не скрывает пристрастия к городской жизни.

Вторая строфа - 10 строк - это нечасто встречающаяся в поэзии XX в. идиллия городская, обволакивающая читателя кольцами «нежной безделицы». Эта часть, в отличие от предыдущей, динамична: точно подобранные слова прямо или косвенно передают движение улиц («служащих бег», 
«быстрые двери аптек», «рысь комсомольца», «нервных трамваев возня»). При этом шум улиц не мешает, а помогает завзятому горожанину сосредоточиться на себе, собственных мыслях; «день ото дня» он становится ближе к себе самому, и, как следствие этой сосредоточенности, возникает возможность писать: «обыкновенный уют, где ундервуды поют». Здесь, кстати, ассоциативно возникает перекличка со стихотворением «Творчество» Анны Ахматовой: то же «сужение» внешних звуков, пока не находится один «все победивший» звук; подобная характеристика творчества: «обыкновенность» уюта пишущих машин отзывается ахматовскими «просто продиктованными строчками» (курсив наш. - E.Б.).

Любовная лирика тоже может быть прочитана как идиллический текст, как ситуация идеального гармоничного общения:

\section{Любовь}

Не красавица: милая женщина ласковым телом приникла.

Как шепчет доверчиво; морщит носик; ёжится зябко.

Как вздыхает удовлетворенно, лепестки очей опуская,

Пальцами худенькими грудь свою давя в изумленье. Будто не верит, что это она - Лёлька! - а не сон,

Будто развратницей кто-то сочтет, а не любимый

В котором всех цветов дыханье, всем мыслям покой.

а не кажется; целует, [11. C. 38].

Однако есть и «непроясненные» идиллии, в которых смещаются жанрообразующие признаки, и можно говорить о трансформации жанра. Жанровая модель идиллии перестала быть статичным образованием. Иллюстрируя черты идиллии в семантически «затемненных» стихотворениях, представляющих собой своеобразный вызов интерпретаторам, мы видим «подполье» идиллии: осталось ядро при искажении второстепенных черт. Рассмотрим отрывок из стихотворения 1924 г. «Нечаянные тучи...»:

И я зализываю культуру,

Как медь.

И весьма определенный покой

Каждодневного быта

Колдует

Шито-крыто

Захолустьем во мне [11. С. 45].

Связность текста здесь обеспечивается не благодаря логическому развертыванию темы, а с помощью ассоциаций между коннотативными значениями слов. Из 7 строк последние 5, упоминающие «покой быта», понятны: именно идиллический покой является для каждого самым целительным чувством, околдовывающим ежедневно, незаметно. Появляющееся в последней строке слово «захолустье» может восприниматься или как перифраз покоя, спокойного быта, или как плеоназм, поскольку «покой колдует захолустьем». Захолустье - это глушь, отдаленное и малонаселенное место. Захолустье - это место, где события, если они есть, тянутся медленно, спокойно. Возможна также коннотация: захолустье - богом оставленное, брошенное место. Такова в советской литературе идиллия как жанр - забыта и брошена, как забыто и брошено такое пространство жизни человека, как захолустье. В 1920-1930-е годы идеологи «новой жизни» ратуют за активную гражданскую позицию, за отказ от частного. Но то ли нужно подлинной культуре? Возвратимся к первым двум строкам:

И я зализываю культуру,

Как медь [11. С. 45]. 
Значить они могут следующее: сама культура дробна, целостность ей придает воспринимающий. Он, поэт, предотвращает процесс окисления, старения культуры через контакт прошлого с настоящим. И как трещины медной утвари для ее сохранности заливают оловом, так и покой быта (здесь идиллическое) выравнивает швы стихийной и неупорядоченной жизни, спасает - созидает культуру. Может быть, здесь «работает» еще один смысл слова: зализывают раны, заживляя их.

Мало того, появляется ассоциация, которая рождается в связи с еще одним употреблением слова «зализываю»: «зализывать как полировать». При этом для Оболдуева важен «способ» этой полировки - покоем! «Лудить» созвучно идиллическому «ладить», оба употребляются в значении «налаживать» и оба слова не называются в стихотворении, но как будто заранее существуют в сознании читателя как опоры - чтобы идиллический смысл текста состоялся.

Две выделенные нами строки обнажают важное для Г. Оболдуева положение о «целительной» роли культуры. Показательно, что этот образ встречается у поэта неоднократно, становясь устойчивым мотивом. Так, в стихотворении под заголовком «Вечер, посвященный Баху» (1924 г.) две последние строчки предпоследней строфы как бы «обнажают», проясняют значимый для автора мотив:

лудится медь культуры:

Бах течёт [11. С. 59].

Обратимся к другому примеру - стихотворению 1927 г. «Недавно, вежливо, бегло...» (отрывок):
Хлебай природу, человек:
Леса, где тлеет соловей,
Удобную небрежность рек,
Куски питательных полей,
Вещей спокойный частокол,
Окружных жизней произвол,
Существование своё
И обаяние её [11. С. 127].

На первый взгляд, перед нами какие-то разрозненные детали, фрагменты, но, взятые вместе: «питательные куски», «хлебай», - они образуют неожиданно цельную картину - картину застолья, трапезы. «Хлебай» - очень «удобное» слово: оно в одинаковой мере относится и к жидкой пище, и к питью - к нераздельности, «интимности» взаимосвязи человека, еды и природы, по определению М. Пришвина. Не в полном объеме и конкретно, как это знакомо читателю по идиллическим текстам, а в неожиданном освещении - соединяясь с темой Родины, превращаясь в здравицу (хлебай, как из ендовы во время застолья). Направленность любви - на Россию природную, возможно, деревенскую. Композиция стихотворения похожа на перевернутую пирамиду, поскольку постепенно «сужаются» масштабные объекты авторской любви. Сначала - леса, реки, поля. Потом - частокол вещей. Сначала описание природы - потом остановка взгляда на человеке. «Окружные» жизни - это жизни окружающих, рифмующиеся (вместе с окружающим частоколом) со сферами идиллической жизни, за которыми начинается другая Родина - огосударствленная. Кажется, что однажды мы уже видели такой «вариант» отказа от официальной любви к Отечеству - в лермонтовском стихотворении «Родина», первая часть которого - отказ от уваровской формулы «православия, самодержавия, народности».

Приложение матрицы лермонтовского «но я люблю...» к стихотворению Оболдуева показывает, насколько здесь эта любовь редуцирована - до сдержанной оценки: «обаяния ее». «Обаяние» предполагает участие субъекта - и здесь он явен через «существование свое». Заметим, как скромно обозначено «место под солнцем»: не жить, а существовать. Задорное «хлебай» первой строки отзывается фразеологизмом, объясняющим горькую жизнь человека, - «несолоно хлебавши».

Однако идиллическое «хлебай» - как приглашение к застолью у Оболдуева - может означать еще и «насыщайся, вбирай без остановки» («рассказывать взахлеб»). Хлебать - это пить бесконтрольно, жадно, свободно - так ненапряжность, извилистость, «произвол» окружающих людей должен сливаться с вольностью, произволом, свободой природы («удобная небрежность рек»). Вот это пафос подлинной идиллии. 
В.И. Козлов отмечает, что система жанров «вырастает из сдвигов» [8. С. 371]. Изучение этих «сдвигов» представляется реальным для изучения лирики XX века. В таком случае наше представление о жанре формируется не «сверху, то есть из теоретического тезиса, а снизу - из многообразия литературного процесса» [1. С. 19]. Устойчивое мнение, что все уже сказано, «возникает в середине $\mathrm{XX}$ века; авторизация уступает место установке на игру любыми чужими контекстами и вовлекает их в поле своего текста» [1. С. 30]. Идиллия в рассмотренных отрывках существует у Г. Оболдуева и как игра, и как архетип, как подсознательный концепт бытия, в жизни не претворенный. Можно говорить, что у Оболдуева существует «подпольный» вариант идиллии, позволяющий говорить не просто о нарушениях жанровых традиций, а о «жанровом споре» [4. С. 42], о «сломанном» жанре.

\section{СПИСОК ЛИТЕРАТУРЫ}

1. Артемова С.Ю. Лирические жанры сегодня. Тверь: тверской государственный университет, 2020.191 с.

2. Афанасьева К.А. Русская ода XVIII века: истоки и эволюция: дис. ... канд. филол. наук: 10.01 .01$. M., 1993. 223 c.

3. Балашова Е.А. «И пастушок, привитый вместо оспы...»: История развития жанра идиллии в русской поэзии XX-XXI вв. Калуга: КГУ им. Циолковского, 2014. 352 с.

4. Верина У.Ю. Обновление жанровой системы русской поэзии конца XX - начала ХХІ веков: дис. ... докт. филол. наук: 10.01.01 М., 2019. 451 с.

5. Глоцер В. Поэт Георгий Оболдуев // Оболдуев Гееоргий. Стихотворения. Поэма / Сост. А.Д. Благинина. Подг. текста И.А. Ахметьева. Вступ. ст. В. Глоцера; М.: Виртуальная галерея, 2005. 608 с.

6. Зырянов О.В. Жанровая стратегия в книге Г. Сапгира «Сонеты на рубашке» // Полилог: Электронный научный журнал, 2009. № 2. С. 88-91.

7. Кихней Л.Г. Из истории жанров русской лирики: Стихотворное послание начала ХХ века. Владивосток: ДВГУ, 1989. 162 с.

8. Козлов В.И. Русская элегия неканонического периода: типология, история, поэтика: дис. ... докт. филол. наук. Ростов-на-Дону, 2013.

9. Лейдерман Н.Л. Теория жанра. Екатеринбург: ИФИОС «Словесник» УРО РАН; Урал. гос. пед. ун-т, 2010. $904 \mathrm{c.}$

10. Леонов И.С. Поэтика русской эпиграммы XVIII - начала XIX века: дис. ... канд. филол. наук: 10.01.01. М., 2006. $210 \mathrm{c}$.

11. Оболдуев Георгий. Стихотворения 20-х годов / сост. А.Д. Благинина; подг. текста и комментарии И.А. Ахметьева. М.: Виртуальная галерея, 2009. 304 с.

12. Фризман Л.Г. Жизнь лирического жанра. М.: Наука, 1973. 166 с.

Поступила в редакцию 28.08.2020

Балашова Елена Анатольевна, доктор филологических наук, доцент кафедры литературы

ФГБОУ ВО «Калужский государственный университет им. К.Э. Циолковского»

248000, Россия, г. Калуга, пер. Воскресенский, 4

E-mail: balashova_ea@mail.ru

\section{E.A. Balashova \\ OBOLDUEV'S IDYLL: THE UNDERGROUND VERSION}

DOI: $10.35634 / 2412-9534-2021-31-3-589-594$

The article gives an interpretation of the early, seemingly difficult texts by Georgy Obolduev. His style is characterized not only by whimsical associative connections, but also by very precise and responsible word usage. This analysis allows us to find traditional idyllic motifs in his seemingly difficult poems.

In the considered passages by G. Obolduev idyll exists as an archetype, as a subconscious and not embodied concept of being. One can say that Obolduev has an "underground" version of idyll. The unusual poetics of the idyllic poems correspond to the poetics of Obolduev's early works with sophisticated wordplay, realistic details, vivid imagery, intertextuality, "style eclecticism" and lexical variety.

The analysis of Obolduev's texts of different periods revealed the important motif of "culture as cure". It is significant that this motif is regular and frequent in Obolduev's works.

Keywords: Russian poetry of the 20th century, Georgy Obolduev, writing style, idyll. 


\section{REFERENCES}

1. Artemova S.Yu. Liricheskiye zhanry segodnya [Lyric genres today]. Tver': tverskoy gosudarstvennyy universitet, 2020, 191 p. (In Russian).

2. Afanas'yeva K.A. Russkaya oda XVIII veka: istoki i evolyutsiya [Russian ode of the 18th century: origins and evolution]: dissertatsiya...kand. filol.n.: 10.01.01. M., 1993, 223 p. (In Russian).

3. Balashova Ye.A. «I pastushok, privityy vmesto ospy...»: Istoriya razvitiya zhanra idillii v russkoy poezii XX-XXI vv. [«And a shepherd boy vaccinated instead of smallpox ...»: The history of the development of the idyllic genre in Russian poetry of the XX-XXI centuries]. Kaluga: KGU im. Tsiolkovskogo, 2014, 352 p. (In Russian).

4. Verina U.Yu. Obnovleniye zhanrovoy sistemy russkoy poezii kontsa XX - nachala XXI vekov [Updating the genre system of Russian poetry at the end of the XX - beginning of the XXI centuries]: dis. ... doktora filol. $\mathrm{n} .:$ 10.01.01 M., 2019, 451 p. (In Russian).

5. Glotser V. Poet Georgiy Obolduyev // Obolduyev Geyeorgiy. Stikhotvoreniya. Poema [Obolduev Georgy. Poems. Poem] / Sost. A.D. Blaginina. Podg. teksta I.A. Akhmet'yeva. Vstup. st. V. Glotsera; M.: Virtual'naya galereya, 2005, 608 p. (In Russian).

6. Zyryanov O.V. Zhanrovaya strategiya v knige G. Sapgira «Sonety na rubashke» [Genre strategy in the book by G. Sapgir «Sonnets on the shirt»] // Polilog: Elektronnyy nauchnyy zhurnal, 2009, No 2. P. 88-91. (In Russian).

7. Kikhney L.G. Iz istorii zhanrov russkoy liriki: Stikhotvornoye poslaniye nachala XX veka [From the history of genres of Russian lyric poetry: A poetic message of the early twentieth century]. Vladivostok: DVGU, 1989, 162 p. (In Russian).

8. Kozlov V. I. Russkaya elegiya nekanonicheskogo perioda: tipologiya, istoriya, poetika [Russian elegy of the noncanonical period: typology, history, poetics]. Diss.na soiskaniye uch.step.doktora filol.n. Rostov-na-Donu, 2013. (In Russian).

9. Leyderman N.L. Teoriya zhanra [Genre theory]. Yekaterinburg: IFIOS «Slovesnik» URO RAN; Ural. gos. ped. unt, 2010, 904 p. (In Russian).

10. Leonov I.S. Poetika russkoy epigrammy XVIII - nachala XIX veka [Poetics of the Russian epigram of the 18th early 19th centuries]: dissertatsiya ... kand.filol.n.: 10.01.01. M., 2006, 210 p. (In Russian).

11. Obolduyev Georgiy. Stikhotvoreniya 20-kh godov [Poems of the 20s]. Sost. A.D. Blaginina. Podg. teksta i kommentarii I.A. Akhmet'yeva. M.: Virtual'naya galereya, 2009, 304 p. (In Russian).

12. Frizman L.G. Zhizn' liricheskogo zhanra [The life of the lyric genre]. M.: Nauka, 1973, 166 p. (In Russian).

Received 28.08.2020

Balashova E.A., Doctor of Philology, Associate Professor at Department of Literature

Kaluga State University named after K.E. Tsiolkovsky

Voskresenskiy lane, 4, Kaluga, Russia, 248000

E-mail: balashova_ea@mail.ru 